\title{
A systematic management algorithm for perioperative complications after robotic assisted partial nephrectomy
}

\author{
James Ryan ${ }^{1}$; Eoin MacCraith ${ }^{1}$; Niall F. Davis ${ }^{2}$; Liza McLornan ${ }^{1}$ \\ ${ }^{1}$ Urology Department, Connolly Hospital, Blanchardstown, Dublin, Ireland; ${ }^{2}$ Urology Department, Austin \\ Hospital, Melbourne, Australia
}

Cite as: Can Urol Assoc J 2019 February 26; Epub ahead of print. http://dx.doi.org/10.5489/cuaj.5750

Published online February 26, 2019

$* * *$

\begin{abstract}
Nephron-sparing surgery (NSS) is the treatment of choice for T1 renal cell carcinoma (RCC). Since the first robotic assisted partial nephrectomy (RAPN) was performed in 2004, NSS is being implemented with increasing frequency. RAPN will likely become the gold standard procedure for T1 RCC due to improved dexterity, enhanced visualization, shorter learning curve, quicker recovery time, and shortened warm ischemic time. Although RAPN appears to be the preferred treatment for select renal tumours, there are notable complications in up to $35 \%$ of cases. While complications associated with RAPN are well-described, there is a lack of literature describing appropriate management strategies. Herein, we review complications associated with RAPN and design an appropriate systematic management algorithm.
\end{abstract}

\section{Introduction}

Nephron sparing surgery (NSS) is the treatment of choice for T1 renal cell carcinoma (RCC). The American Urological Association and European Association of Urology advocate nephron preservation when suitable as this approach reduces the risk of chronic kidney disease.(1,2) Open partial nephrectomy (OPN), laparoscopic partial nephrectomy (LPN) and robotic assisted partial nephrectomy (RAPN) are the currently available surgical options for excision of T1 RCC. Although LPN has demonstrated excellent oncological outcomes and improved recovery times; it has not been widely implemented due to technical difficulties in comparison to OPN and LPN is therefore generally limited to high-volume centres.(3)

The first RAPN was performed in Germany in 2004 and is now being performed with increasing frequency.(4) Robotic surgery is associated with improved dexterity, better visualisation and ergonomic advantages making minimally invasive partial nephrectomy more accessible to urologists. In addition, RAPN has less warm ischaemic time (WIT) compared to OPN and LPN which may reduce the risk of chronic kidney disease.(5)(6) 
Although RAPN appears to be the preferred treatment for select renal tumours, there are notable complications in up to 35\% of cases.(7) The vast majority are classified as lowgrade complications with $50 \%$ being medically related.(8) High grade complications, where an intervention is required has an incidence of 6-8\% after RAPN.(9,10) Although complications associated with RAPN are well described, there is a lack of data describing appropriate management strategies. Herein, we discuss complications associated with RAPN and design an appropriate systematic management algorithm.

\section{Methods}

A systematic literature search was performed using the Pubmed and Embase databases to identify peer reviewed articles that studied peri-operative complications related to RAPN. The search was conducted on the $26^{\text {th }}$ September 2018. The search was performed using the following search algorithm: 'partial nephrectomy' and 'complications' and 'robot' and 'management'. Studies between 2008 and September 2018 were included. Publications comparing complications between RAPN, LPN and OPN were included. Case reports and case series were excluded. Publications not in the English language were included if the data could be interpreted. Two authors (JR and EMacC) examined the title and the abstracts and full texts of potentially eligible articles were examined in detail. References in each paper were reviewed for suitability to be included in the literature review. From the literature search 30 papers were suitable for this narrative based review. The main data analysed were types and incidence of complications specifically related to RAPN and the respective management of each. Medical complications were excluded.

\section{Results}

\section{Predictive factors}

Current guidelines recommend a detailed risk assessment prior to partial nephrectomy to identity patients that are at an increased complication risk.(1)(2) Several factors relating to the patient, tumour and the surgeon affect the peri-operative outcome. The most common patient factors associated with increased risk of peri-operative complications and lower 5year survival rates are male gender, increased age, lower pre-operative haemoglobin and presence of co morbidities such as uncontrolled hypertension, diabetes, respiratory or cardiovascular disease.(11-13) Mari et al. performed a large prospective multi-centre study looking at predictive factors for post-operative complications in 979 patients who underwent a partial nephrectomy. However only 117 of these patients underwent a RAPN and nephrometry scores were not reported. (11) Several studies have utilised predictive nephrometry (C-index, RENAL and PADUA) scoring systems based on tumour characteristics with some success.(12,15,16) Location of the tumour adjacent to the hilum, involvement of the collecting system and increasing tumour size over time demonstrated a statistically significant association with peri-operative complications. A higher nephrometry score is also associated with a decrease in estimated glomerular filtration rate (eGFR) in the immediate post-operative period.(13) However, all studies were performed retrospectively and were not used the in the pre-operative planning of every case. 
RAPN has significantly decreased the learning curve for laparoscopic tasks such as suturing compared to traditional laparoscopic surgery. For LPN, an estimated 100-150 cases are required to overcome the learning curve compared to $\leq 35$ cases for RAPN.(15) A more favourable learning curve may decrease complications relating to the surgeon's experience as demonstrated in one study where there was a reduction in estimated blood loss, length of stay, post-operative complications and conversion rate as the surgeon's learning curve improved.(16)

\section{Complications}

Peri-operative complications are classified according to the Clavien-Dindo system.(17) Clavien-Dindo Grades 3-5 will be the main focus of this narrative review with exclusion of medical complications. Studies describe an overall peri-operative complication rate of $7 \%$ $35 \%$ for RAPN.(5,7,15,18) This wide range is likely due to under-reporting of lower grade (Clavien-Dindo 1-2) complications among groups. The incidence of higher grade complications (i.e. Clavien-Dindo 3-5) varies from 3\%-8\% when medical complications are excluded.(9,10,19,20) A step-wise management algorithm for post-operative complications specifically associated with RAPN is illustrated in figure 2.

\section{Intra-operative complications}

Intra-operative complications for RAPN are infrequent and are typically due to haemorrhage. Estimated blood loss intraoperatively is usually between $150-350 \mathrm{mls} .(10,20)$ One study reviewed 886 patients undergoing RAPN and described an incidence of $2.6 \%(n=23)$ for intra-operative complications. Nine were related to haemorrhage requiring blood transfusion of which 2 transfusions were due to a venotomy and 2 were due to an unclamped accessory renal artery. In addition, 1 transfusion occurred due to an inferior epigastric artery injury after insertion of a laparoscopic trochar and 4 transfusions were due to bleeding in the renal bed.(21) Management of bleeding is dependent on the location. A contrast enhanced CT will aid in the pre-operative planning and identification of hilar structures. Benway et al. advise that meticulous haemostatic measures can be performed once the mass has been excised such as cauterization and suturing of the renal bed with placement of sliding clip renorrhaphy sutures.(22) In this study the renal bed of 13 RAPN were closed with traditional tied sutures and sliding clip renorrhaphy was performed on 37 RAPN. The use of sliding clip renorrhaphy resulted in significant reductions in operative time and WIT. In cases of large volume intraoperative haemorrhage conversion to laparoscopic or open radical nephrectomy may be required.(23)

Other associated intra-operative complications include visceral injuries. Bowel injury rarely occurs, and the incidence rate is $0.25 \%$.(24) Manipulation of the bowel during surgery should be performed gently with atraumatic instruments. Small lacerations in the bowel with no spillage of bowel content into the abdomen can be closed primarily if identified at the time of surgery. Larger full thickness lacerations or ones diagnosed post-operatively may require resection and input should be sought from a colorectal surgeon. Splenic injuries during 
RAPN occur in around $0.08 \%$ of cases.(24) Splenic injuries can occur due to manipulation of the left kidney when traction is exerted on the splenic ligaments. Treatment of splenic injuries is dependent on the severity of the injury. Electro-cautery and haemostatic agents are used to control bleeding however if this fails a splenectomy is required. Hepatic injury is typically related to a thermal injury or laceration from retraction. In general, thermal injuries do not require any intervention. Hepatic lacerations cause significant bleeding and should be initially addressed with electrocautery and haemostatic agents. Larger lacerations with uncontrolled bleeding or damage to the biliary system should involve a hepato-biliary surgeon. Injury to the pancreas is a rare occurrence and capsular injuries can be closed primarily. However, pancreatic leaks may require a partial pancreatectomy and patients require close postoperative monitoring for pancreatitis. Incisions above the $12^{\text {th }}$ rib can result in pleural or diaphragmatic injuries. Pneumothorax during RAPN occurs infrequently and the reported incidence rate is $0.75 \%$.(25) Management of a pneumothorax should be in consultation with a cardiothoracic surgeon or respiratory physician as carefully selected cases can be managed conservatively. A pneumothorax causing haemodynamic instability or respiratory compromise will require a chest drain and serial chest radiographs to ensure resolution.

\section{Postoperative complications}

The most common Clavien-Dindo grade 3-5 post-operative complications are bleeding requiring blood transfusion or surgical/radiological intervention, urine leak, acute kidney injury, arteriovenous (AV) fistula and pseudo-aneurysm.

Re-bleeding during the post-operative period is relatively common after RAPN. In one large study among 400 patients, $15.3 \%(n=63)$ developed a post-operative complication; of which $47 \%(n=29)$ of all complications were due to bleeding requiring blood transfusion.(19) This study collected data retrospectively on a prospectively maintained database and gave a detailed description on their operative technique. However they did not comment on the patient demographics and operative factors that were specifically associated with an increased risk of post-operative haemorrhage. Management of post-operative haemorrhage is dependent on the volume of blood loss and can vary from conservative, to blood transfusion to angio-embolization or emergency nephrectomy. Hyams et al reviewed 998 patients undergoing RAPN and found an incidence rate of $1.7 \%$ for renal artery pseudoaneurysms and $0.3 \%$ for arteriovenous fistulas.(26) Renal artery pseudo-aneurysms arise from intra-operative arterial trauma resulting in communication with the extravascular space or formation of a fistula with the collecting system. Patients typically present at day 14 postoperatively with symptoms of haematuria and/or flank pain. Arterio-venous fistulas (AVF) occur less frequently than renal artery pseudo-aneurysms. Most AVFs are asymptomatic but can also present with symptoms of pain, haematuria, hypertension or high-output cardiac failure. Angio-embolization is the treatment of choice for an actively bleeding vessel, AVF or pseudo-aneurysm when interventional radiology is readily available as surgical revisions are more likely to result in a completion nephrectomy. Selective angio-embolization is effective for the management of arterio-venous fistulas and pseudo-aneurysms in $\leq 95 \%$ of cases.(26) 
This is the largest study to date looking at AVF's and pseudo-aneurysms post partial nephrectomy. However this multi-centre study included both LAPN and RAPN and did not compare the outcomes of both separately. New renorrhaphy techniques providing better closure of the renal bed may also decrease the incidence of this complication.

Urine leak is associated with larger, more complex tumours that are centrally located or near the renal collecting system. Urine leak is a relatively rare complication in comparison to OPN or LPN (0.5\%-4\% for RAPN versus $1 \%-16 \%$ for LPN versus $1 \%-17 \%$ for OPN). $(5,7,24,27)$ This is more than likely due to enhanced vision and improved dexterity from robotic surgery in conjunction with novel techniques for closure of the renal capsule such as sliding clip renorrhaphy to provide a high tensile closure.(22) Higher tumour complexity necessitating OPN may also contribute to the differences in urinary leak rate.(13) Symptoms and signs of a urine leak include increased drain output, fever, abdominal pain and peritonitis. The time at presentation is variable with a median of 13 days (range of 3 - 32 days).(27)

Caputo et al referred to three key principles involved in the management of a postoperative urine leak:

1) Drainage of urinoma

2) Unobstructed distal urinary flow

3) Prevention of infection.(28)

This management strategy is achievable with a percutaneous drain, ureteric stent or urethral catheter depending on the injury. For persistent urine leaks urinary diversion with a percutaneous nephrostomy may be necessary to facilitate healing. Percutaneous nephrostomy in this patient cohort can be difficult as typically the renal pelvis is not dilated due to the urine leak. Erlich et al reviewed 752 who underwent partial nephrectomy of which 2.8\% $(n=21)$ experience a urine leak post operatively. Four of the patients had spontaneous resolution of the urine leak, one patient underwent a nephrectomy and 16 patients were treated with retrograde ureteric stents. Out of the 16 patients who required a ureteric stent, one patient required insertion of a percutaneous nephrostomy.(29) This study is retrospective and only looked at complications from LPN and OPN. Erlich et al. also compared a number of surgeons over a 30 year period and could not exclude different surgical technique as an attributable factor. In the vast majority of cases drainage of the urinoma is sufficient to allow healing of the collecting system defect.(30) Collecting system strictures may inhibit unobstructed distal urinary flow even in the presence of a ureteric stent and drainage of isolated calyces may be necessary.

Acute kidney injury is more common in patients with pre-existing renal disease, in patients with solitary kidneys and in patients with bilateral tumours. Acute kidney injury occurs as a result of acute tubular necrosis secondary to global renal ischaemia. Methods to reduce renal ischaemia involve decreasing warm ischaemic time and reducing the effects of decreased renal perfusion by early unclamping of the artery which decreases the rate of acute kidney injury. Importantly, this should be counterbalanced with the increased risk of bleeding. Warm ischaemia time should not exceed 25 minutes for partial nephrectomy.(31) Prolonged warm ischaemic times has been shown to negatively impact on renal function post 
operatively. Reduced renal function has been shown to last at least one year after a prolonged ischaemic time during partial nephrectomy.(31) One method for reducing the effects of ischaemia cooling the kidney with ice and cooling should be considered if the anticipated ischaemic time is $>25$ minutes. Treatment of an acute kidney injury involves reducing further insult to the kidney by ensuring adequate hydration, avoiding hypotension and avoiding nephrotoxic agents in consultation with a renal physician. Although the risk of chronic kidney disease is significantly less with partial nephrectomy compared to radical nephrectomy, it is still a relatively common complication. Kim et al reported a $6.2 \%$ incidence of new onset CKD after partial nephrectomy .(32) Khalifeh et al. demonstrated upstaging in CKD $\geq 1$ class after partial nephrectomy in $20.2 \%$ of patients (25). This study was performed retrospectively. Of the 427 patients that underwent a RAPN in this centre, only 134 were suitable as patients were required to have a minimum of two year follow up.

\section{Conclusion}

Current guidelines recommend an organ preserving procedure whenever technically possible. RAPN is associated with less complications in comparison to OPN and LPN. Urologists should be familiar with predictive factors for complications associated with RAPN so that they can be promptly recognised and addressed during the peri-operative period. A stepwise management algorithm provides appropriate guidance to urologists for managing perioperative complications after RAPN. 


\section{References}

1. Merseburger AS, Herrmann TRW, Shariat SF, Kyriazis I, Nagele U, Traxer O, et al. EAU Guidelines on Robotic and Single-site Surgery in Urology. Eur Urol [Internet]. 2013;64(2):277-91. Available from: http://www.sciencedirect.com/science/article/pii/S0302283813005022

2. Campbell SC, Novick AC, Belldegrun A, Blute ML, Chow GK, Derweesh IH, et al. Guideline for management of the clinical T1 renal mass. J Urol. 2009 Oct;182(4):1271-9.

3. Reifsnyder JE, Ramasamy R, Ng CK, DiPietro J, Shin B, Shariat SF, et al. Laparoscopic and Open Partial Nephrectomy: Complication Comparison Using the Clavien System. JSLS J Soc Laparoendosc Surg [Internet]. 2012;16(1):38-44. Available from: http://www.ncbi.nlm.nih.gov/pmc/articles/PMC3407455/

4. Gettman MT, Blute ML, Chow GK, Neururer R, Bartsch G, Peschel R. Roboticassisted laparoscopic partial nephrectomy: technique and initial clinical experience with DaVinci robotic system. Urology. 2004 Nov;64(5):914-8.

5. Benway BM, Bhayani SB, Rogers CG, Dulabon LM, Patel MN, Lipkin M, et al. Robot assisted partial nephrectomy versus laparoscopic partial nephrectomy for renal tumors: a multi-institutional analysis of perioperative outcomes. J Urol. 2009 Sep;182(3):86672.

6. Vittori G. Open versus robotic-assisted partial nephrectomy: a multicenter comparison study of perioperative results and complications. World J Urol [Internet]. 2014;32(1):287-93. Available from: https://doi.org/10.1007/s00345-013-1136-x

7. Ellison JS, Montgomery JS, Wolf JSJ, Hafez KS, Miller DC, Weizer AZ. A matched comparison of perioperative outcomes of a single laparoscopic surgeon versus a multisurgeon robot-assisted cohort for partial nephrectomy. J Urol. 2012 Jul;188(1):45-50.

8. Wülfing C, Humke U. Offene und minimal-invasive partielle Nephrektomie. Urologe [Internet]. 2014;53(7):960-7. Available from: https://doi.org/10.1007/s00120-0143512-6

9. Benway BM, Bhayani SB, Rogers CG, Porter JR, Buffi NM, Figenshau RS, et al. Robot-Assisted Partial Nephrectomy: An International Experience. Eur Urol [Internet]. 2010;57(5):815-20. Available from:

http://www.sciencedirect.com/science/article/pii/S0302283810000229

10. Aboumarzouk OM, Stein RJ, Eyraud R, Haber G-P, Chlosta PL, Somani BK, et al. Robotic Versus Laparoscopic Partial Nephrectomy: A Systematic Review and MetaAnalysis. Eur Urol [Internet]. 2012;62(6):1023-33. Available from: http://www.sciencedirect.com/science/article/pii/S0302283812007397

11. Mari A, Antonelli A, Bertolo R, Bianchi G, Borghesi M, Ficarra V, et al. Predictive factors of overall and major postoperative complications after partial nephrectomy: Results from a multicenter prospective study (The RECORd 1 project). Eur J Surg Oncol. 2017 Apr;43(4):823-30.

12. Mathieu R, Verhoest G, Droupy S, Taille A, Bruyere F, Doumerc N, et al. Predictive factors of complications after robot-assisted laparoscopic partial nephrectomy: a retrospective multicentre study. BJU Int [Internet]. 2013 May 9;112(4):E283-9. Available from: https://doi.org/10.1111/bju.12222

13. Reddy UD, Pillai R, Parker RA, Weston J, Burgess NA, Ho ETS, et al. Prediction of complications after partial nephrectomy by RENAL nephrometry score. Ann R Coll 
Surg Engl [Internet]. 2014 Sep 4;96(6):475-9. Available from:

http://www.ncbi.nlm.nih.gov/pmc/articles/PMC4474202/

14. Hew MN, Baseskioglu B, Barwari K, Axwijk PH, Can C, Horenblas S, et al. Critical appraisal of the PADUA classification and assessment of the R.E.N.A.L. nephrometry score in patients undergoing partial nephrectomy. J Urol. $2011 \mathrm{Jul} ; 186(1)$ :42-6.

15. Wang L, Lee BR. Robotic partial nephrectomy: current technique and outcomes. Int J Urol. 2013 Sep;20(9):848-59.

16. Kaouk JH, Hillyer SP, Autorino R, Haber G-P, Gao T, Altunrende F, et al. 252 Robotic Partial Nephrectomies: Evolving Renorrhaphy Technique and Surgical Outcomes at a Single Institution. Urology [Internet]. 2011;78(6):1338-44. Available from: http://www.sciencedirect.com/science/article/pii/S009042951102200X

17. Dindo D, Demartines N, Clavien P-A. Classification of surgical complications: a new proposal with evaluation in a cohort of 6336 patients and results of a survey. Ann Surg. 2004 Aug;240(2):205-13.

18. Spana G, Haber G-P, Dulabon LM, Petros F, Rogers CG, Bhayani SB, et al. Complications after robotic partial nephrectomy at centers of excellence: multiinstitutional analysis of 450 cases. J Urol. 2011 Aug;186(2):417-21.

19. Kaouk JH, Khalifeh A, Hillyer S, Haber G-P, Stein RJ, Autorino R. Robot-assisted Laparoscopic Partial Nephrectomy: Step-by-step Contemporary Technique and Surgical Outcomes at a Single High-volume Institution. Eur Urol [Internet]. 2012;62(3):553-61. Available from: http://www.sciencedirect.com/science/article/pii/S0302283812005970

20. Bertolo R, Autorino R, Simone G, Derweesh I, Garisto JD, Minervini A, et al. Outcomes of Robot-assisted Partial Nephrectomy for Clinical T2 Renal Tumors: A Multicenter Analysis (ROSULA Collaborative Group). Eur Urol. 2018 Aug;74(2):226-32.

21. Tanagho YS, Kaouk JH, Allaf ME, Rogers CG, Stifelman MD, Kaczmarek BF, et al. Perioperative Complications of Robot-assisted Partial Nephrectomy: Analysis of 886 Patients at 5 United States Centers. Urology [Internet]. 2013;81(3):573-80. Available from: http://www.sciencedirect.com/science/article/pii/S0090429512015051

22. Benway BM, Wang AJ, Cabello JM, Bhayani SB. Robotic partial nephrectomy with sliding-clip renorrhaphy: technique and outcomes. Eur Urol. 2009 Mar;55(3):592-9.

23. Nepple KG, Sandhu GS, Rogers CG, Allaf ME, Kaouk JH, Figenshau RS, et al. Description of a multicenter safety checklist for intraoperative hemorrhage control while clamped during robotic partial nephrectomy. Patient Saf Surg. 2012 Apr;6:8.

24. Zargar H, Allaf ME, Bhayani S, Stifelman M, Rogers C, Ball MW, et al. Trifecta and optimal perioperative outcomes of robotic and laparoscopic partial nephrectomy in surgical treatment of small renal masses: a multi-institutional study. BJU Int [Internet]. 2015;116(3):407-14. Available from: http:https://doi.org/10.1111/bju.12933

25. Khalifeh A, Autorino R, Eyraud R, Samarasekera D, Laydner H, Panumatrassamee K, et al. Three-year oncologic and renal functional outcomes after robot-assisted partial nephrectomy. Eur Urol. 2013 Nov;64(5):744-50.

26. Hyams ES, Pierorazio P, Proteek O, Sukumar S, Wagner AA, Mechaber JL, et al. Iatrogenic Vascular Lesions After Minimally Invasive Partial Nephrectomy: A Multiinstitutional Study of Clinical and Renal Functional Outcomes. Urology [Internet]. 2011;78(4):820-6. Available from: http://www.sciencedirect.com/science/article/pii/S009042951100584X

27. Potretzke AM, Knight BA, Zargar H, Kaouk JH, Barod R, Rogers CG, et al. Urinary 
fistula after robot-assisted partial nephrectomy: a multicentre analysis of 1791 patients. BJU Int. 2016 Jan;117(1):131-7.

28. Caputo PA, Kaouk J. Management of complications arising from the treatment of small renal masses. Int J Surg [Internet]. 2016;36:583-7. Available from: http://www.sciencedirect.com/science/article/pii/S1743919116300231

29. Erlich T, Abu-Ghanem Y, Ramon J, Mor Y, Rosenzweig B, Dotan Z. Postoperative Urinary Leakage Following Partial Nephrectomy for Renal Mass: Risk Factors and a Proposed Algorithm for the Diagnosis and Management. Scand J Surg [Internet]. 2016 Jul 18;106(2):139-44. Available from: https://doi.org/10.1177/1457496916659225

30. Gonzalez-Aguirre AJ, Durack JC. Managing Complications Following NephronSparing Procedures for Renal Masses. Tech Vasc Interv Radiol [Internet]. 2016;19(3):194-202. Available from: http://www.sciencedirect.com/science/article/pii/S1089251616300166

31. Porpiglia F, Fiori C, Bertolo R, Angusti T, Piccoli GB, Podio V, et al. The effects of warm ischaemia time on renal function after laparoscopic partial nephrectomy in patients with normal contralateral kidney. World J Urol [Internet]. 2012 Apr;30(2):257-63. Available from: https://doi.org/10.1007/s00345-011-0729-5

32. Kim CS, Bae EH, Ma SK, Kweon S-S, Kim SW. Impact of partial nephrectomy on kidney function in patients with renal cell carcinoma. BMC Nephrol. 2014 Nov;15:181. 


\section{Figures and Tables}

Fig. 1. Preferred reporting items in systematic reviews and meta-analyses (PRISMA) diagram.

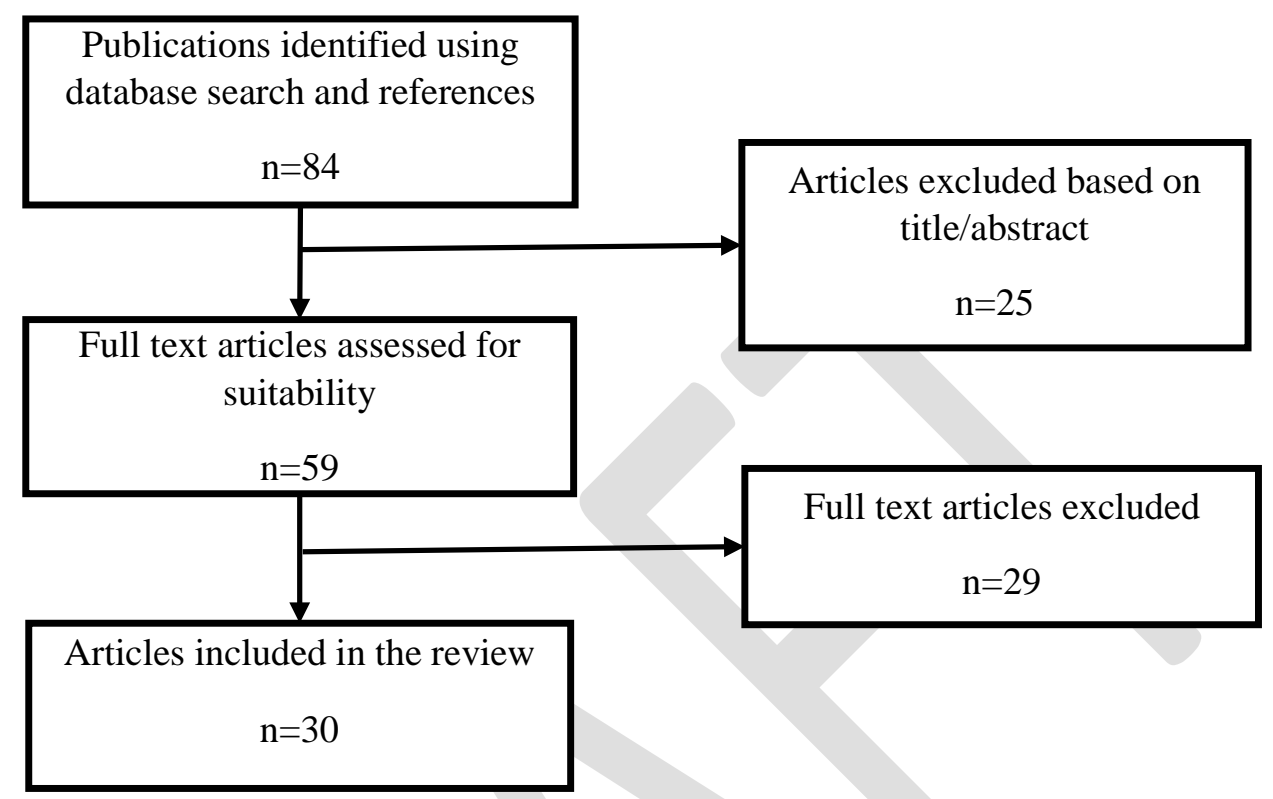




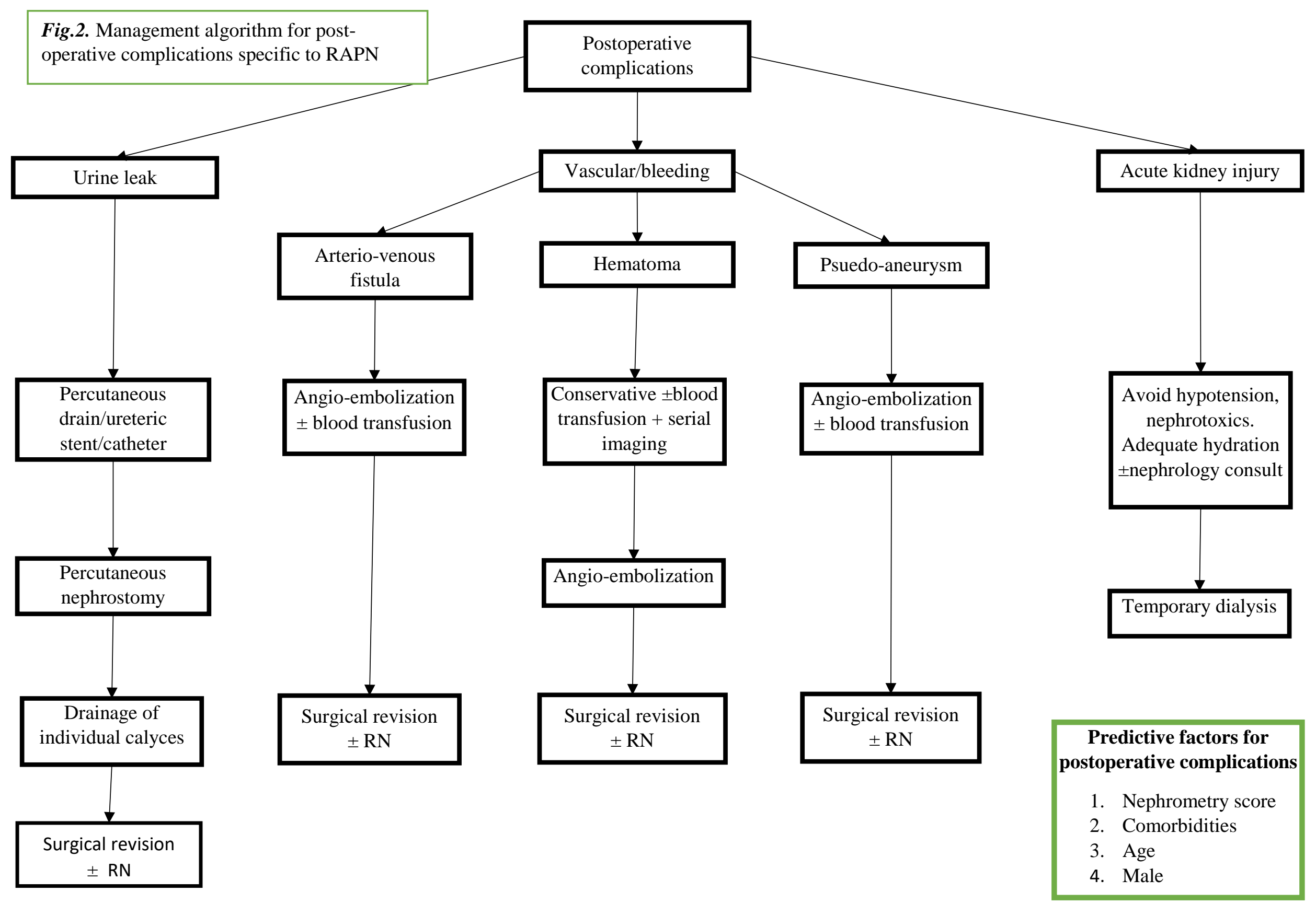




\begin{tabular}{|c|c|c|}
\hline Study & Study design & $\begin{array}{l}\text { Level of } \\
\text { evidence }\end{array}$ \\
\hline${\text { Campbell et } \mathrm{al}^{2}}^{2}$ & Systematic review & $2 \mathrm{~A}$ \\
\hline${\text { Reifsnyder et } \mathrm{al}^{3}}^{3}$ & Retrospective cohort study & $2 B$ \\
\hline${\text { Gettman et } \mathrm{al}^{4}}^{4}$ & Case series & 4 \\
\hline Benway, Bhayani et al $^{5}$ & Retrospective cohort study & $2 B$ \\
\hline 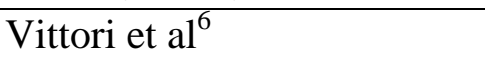 & Retrospective cohort study & $2 \mathrm{~B}$ \\
\hline Ellison et $\mathrm{al}^{7}$ & Retrospective cohort study & 2B \\
\hline Wülfing et $\mathrm{al}^{8}$ & Narrative review & $2 B$ \\
\hline Benway, Bhayani et al $^{9}$ & Retrospective cohort study & $2 \mathrm{~B}$ \\
\hline Aboumarzouk et al ${ }^{10}$ & Systematic review & $2 \mathrm{~A}$ \\
\hline Mari et al ${ }^{11}$ & Retrospective cohort study & $1 \mathrm{~B}$ \\
\hline 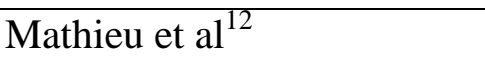 & Retrospective cohort study & $2 \mathrm{~B}$ \\
\hline 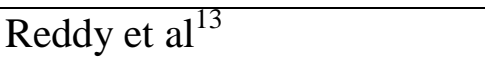 & Retrospective cohort study & $2 B$ \\
\hline Hew et $\mathrm{al}^{14}$ & Retrospective cohort study & $2 B$ \\
\hline Wang et al ${ }^{15}$ & Narrative review & $2 B$ \\
\hline Kaouk et al ${ }^{16}$ & Retrospective cohort study & $2 \mathrm{~B}$ \\
\hline Spana et al ${ }^{18}$ & Retrospective cohort study & $2 \mathrm{~B}$ \\
\hline Kaouk, Khalifeh et al ${ }^{19}$ & Prospective cohort study & $2 \mathrm{~B}$ \\
\hline Bertolo et $\mathrm{al}^{20}$ & Retrospective cohort study & $2 B$ \\
\hline Tanagho et $\mathrm{al}^{21}$ & Prospective cohort study & $2 \mathrm{~A}$ \\
\hline Benway, Wang et al $^{22}$ & Case control study & $3 B$ \\
\hline${\text { Nepple et } \mathrm{al}^{23}}^{23}$ & Expert opinion & 5 \\
\hline Zargar et $\mathrm{al}^{24}$ & Retrospective cohort study & $2 \mathrm{~B}$ \\
\hline 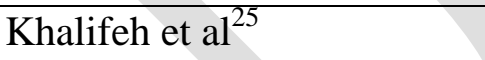 & Retrospective cohort study & $2 \mathrm{~B}$ \\
\hline Hyams et $\mathrm{al}^{26}$ & Retrospective cohort study & $2 \mathrm{~B}$ \\
\hline 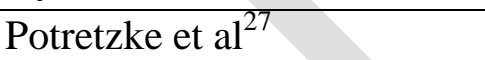 & Retrospective cohort study & $2 B$ \\
\hline Caputo et $\mathrm{al}^{28}$ & Narrative review & $2 B$ \\
\hline Erlich et $\mathrm{al}^{29}$ & Retrospective cohort study & $2 B$ \\
\hline${\text { Gonzalez-Aguirre et } \mathrm{al}^{30}}^{30}$ & Narrative review & $2 B$ \\
\hline${\text { Porpiglia et } \text { al }^{31}}^{1}$ & Prospective cohort study & $2 \mathrm{~B}$ \\
\hline 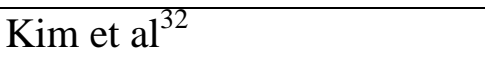 & Retrospective cohort study & $2 \mathrm{~B}$ \\
\hline
\end{tabular}

